\title{
Expiratory Muscle Strength Training improves measures of pressure generation and cough strength in a patient with Myotonic Dystrophy Type 1
}

\section{Abstract}

Expiratory muscle strength training (EMST) exercise programmes aim to improve respiratory function by increasing the force generating capability of expiratory muscles by resistance training. In neuromuscular conditions, in which cough flow generation is often decreased, there is increasing interest in EMST as a therapeutic intervention. We present data showing efficacy of EMST in a patient with adult onset Myotonic Dystrophy Type 1 (DM1). A domiciliary training programme ( 5 days per week over 32 weeks) resulted in increases in maximum expiratory mouth pressure (from $15 \mathrm{cmH}_{2} \mathrm{O}$ to $38 \mathrm{cmH}_{2} \mathrm{O}$ ) and peak cough flow (300L/min to $390 \mathrm{~L} / \mathrm{min})$. Improvements were also seen in maximum inspiratory mouth pressure $\left(26 \mathrm{cmH}_{2} \mathrm{O}\right.$ to $\left.52 \mathrm{cmH}_{2} \mathrm{O}\right)$ and sniff nasal inspiratory pressure $\left(40 \mathrm{cmH}_{2} \mathrm{O}\right.$ to $69 \mathrm{cmH}_{2} \mathrm{O}$ ). No changes were detected in speech or swallowing. This novel study demonstrates that cough flow generation in DM1 may be increased by a programme of expiratory muscle training. A clinical trial of EMST in DM1 is warranted.

Key words: Myotonic Dystrophy Type 1, cough peak flow, maximum expiratory pressure, dysphagia, expiratory muscle strength training

\section{Introduction}

Myotonic dystrophy type 1 (DM1) is the most prevalent neuromuscular disease in adults and affects 1 in 8000 people worldwide [1]. It is a progressive multisystem genetic disorder caused by an unstable trinucleotide CTG repeat expansion in untranslated DNA of the DMPK gene. There is a modest positive correlation between the CTG repeat expansion, an earlier 
age of symptom onset, and disease severity [2]. People can be divided into four main subtypes of DM1: congenital, childhood-onset, adult-onset and late onset based on the age of onset of their symptoms with younger onset patients having increased CTG repeats and more severe disease severity.

The characteristic features of adult-onset DM1 include onset in the late teens and early twenties, weakness of finger flexion and ankle dorsiflexors as well as weakness and wasting of the face, neck and bulbar ${ }^{1}$ muscles. Myotonia may additionally affect hand grip function and speech production [2]. Weakness and/or myotonia of the respiratory muscles and a susceptibility to aspiration from swallowing problems increase the risk of respiratory infections and failure [3]. Aspiration pneumonia is common in individuals with more advanced disease and results in high levels of morbidity and mortality $[2,4,5]$. Respiratory failure secondary to aspiration pneumonia accounts for up to $60 \%$ of deaths in DM1, with a mean age of death at 54 years [6].

Current strategies for bulbar and respiratory impairment in DM1 include assisted ventilation, cough augmentation such as mechanical insufflation-exsufflation (MI:E), compensatory swallowing strategies for food, drink, and saliva, and feeding tube placement [7]. These interventions are targeted to compensate for loss of function, however there is no current evidence that these interventions prolong quality or length of life.

The role of bulbar and respiratory muscle exercise in DM1 is relatively unexplored, although studies have shown a beneficial role of whole-body exercise in maintaining function and improving overall survival [8-14]. The implementation of mild-moderate intensity exercise is supported by consensus-based care recommendations [7].

\footnotetext{
${ }^{1}$ The term bulbar in this context refers to any muscles associated with speech or swallowing.
} 
Expiratory muscle strength training (EMST) is an exercise technique which uses resistive forces deployed at the mouth to train muscles involved in forceful expiration. It has been shown to improve subglottic air pressure generation and airway clearance abilities in several groups of people living with neurological disease including stroke [15] and Parkinson's disease $[16,17]$ as well improve aspects of swallowing $[15,16]$ Data from these studies showed that EMST improved strength of the trained muscles, improved airway safety during swallowing in people with dysphagia, was well tolerated, and safe [18].

EMST is not only safe and feasible in amyotrophic lateral sclerosis (ALS), but has shown positive outcomes $[19,20]$. In an individual with ALS, subglottic air pressure generation increased by $102 \%$ after eight weeks of EMST [19]. In a pilot study of 25 people living with ALS, a 5-week program of EMST led to significant improvements in maximum expiratory pressure generation and swallow kinematics in all individuals, and, in one individual, improved airway protection [20]. In the only randomised control trial of EMST in ALS, the primary outcome measure (maximum expiratory pressure) and secondary outcome measures (combined swallowing safety and efficiency score) significantly increased in the treatment group [21].

These treatment effects witnessed across the bulbar and respiratory systems in neurodegenerative conditions supported trialling a programme of EMST in a patient with DM1 with the aim to improve airway clearance abilities and swallowing safety

\section{Case Report}

\subsection{Patient Information}


A 46-year-old woman with adult-onset DM1 attended our neuromuscular centre for annual multidisciplinary team (MDT) review describing symptoms of (progressive) dysphagia which raised concerns regarding an associated increased risk of aspiration.

A genetic diagnosis of DM1 had been confirmed five years prior. She had undergone cataract removal aged 32 years and had experienced 6 years of progressive hand grip myotonia and altered speech. At the time of assessment for intervention with EMST the patient was independently mobile with no history of trips or falls, with mild weakness of finger flexion and ankle dorsiflexion.

There had been no deterioration in spirometry, videofluoroscopy or bulbar clinical assessments over the previous 12 months. Though her cough peak flow was relatively reduced, it was above the threshold for requiring machine-assisted cough augmentation such as MI:E. . We hypothesised that EMST would improve measures of swallow function and cough strength.

\subsection{Methods}

Baseline respiratory function, voluntary cough and bulbar outcome measures, including videofluoroscopy, were collected on the same day the training programme was initiated. See Table 1.

\subsubsection{The EMST150 $15 \mathrm{TM}$}

The EMST150 ${ }^{\mathrm{TM}}$ (Aspire Products, LLC, NC, USA) is a one-way, spring-loaded valve device capable of providing resistance from 24 to $150 \mathrm{cmH}_{2} \mathrm{O}$, adjusted in increments of $3.75 \mathrm{cmH}_{2} \mathrm{O}$ by a manual $1 / 8$ turn of the dial which controls the valve. An integrated 
resistance valve opens only when sufficient expiratory flow exceeds the goal pressure which corresponds to its indicator of $24 \mathrm{cmH}_{2} \mathrm{O}$ plus any multiple of $3.75 \mathrm{~cm} \mathrm{H}_{2} \mathrm{O}$.

\subsubsection{The Training Program}

A pragmatic programme was designed in which compliance to the training schedule was achieved prior to a stepwise increase in resistance pressures. Resistance pressures were increased in multiples of $3.75 \mathrm{~cm}^{2}$ according to patient ability rather than a pre-determined sequence. The training aim was for 25 repetitions at a given pressure in a single session [22]. Each session was to be broken into 5 blocks of 5 repetitions with a 2-minute rest between each block. At initiation, the patient was asked to perform 1 block of 5 repetitions per day, increasing by one block per week to 5 blocks per session, once each day, five days a week. Focused training on technique was provided in the first week. Adherence was self-reported via a home diary. The resistance pressure was increased when the patient was able to overcome the increased valve resistance for all 5 blocks of 5 successive repetitions without obvious fatigue or side-effect.

The initial session was completed with cardiac monitoring to ensure no adverse responses. Respiratory outcome measures were repeated one week after training on the maximum dose. Bulbar and respiratory measures listed in Table 1 were repeated at week 13 and again at week 32.

\subsection{Results}

\subsubsection{The EMST Protocol}

The patient achieved compliance ( 5 blocks of 5 repetitions, once per day, five days per week) by week 5 . Three different mouthpiece interfaces were trialled to minimise air leak at 
the mouth: the original blue EMST ${ }^{\mathrm{TM}}$ mouthpiece, the EMST ${ }^{\mathrm{TM}}$ contoured comfort mouthpiece and a 1030 TRU-FIT ${ }^{\mathrm{TM}}$ soft plastic mouthpiece, the latter being the most effective. Resistance was increased as illustrated in Table 2. EMST ${ }^{\mathrm{TM}}$ settings were calculated from the EMST150 calibration guide (https://www.emst150.com/wpcontent/uploads/2019/11/Calibration.pdf) based on manual turning of the EMST dial.

\subsubsection{Clinical Outcomes}

An improvement in maximum inspiratory pressure, MIP $\left(26 \mathrm{cmH}_{2} 0\right.$ to $\left.42 \mathrm{cmH}_{2} \mathrm{O}\right)$, maximum expiratory pressure, MEP $\left(15 \mathrm{cmH}_{2} \mathrm{O}\right.$ to $\left.26 \mathrm{cmH}_{2} \mathrm{O}\right)$, sniff nasal inspiratory pressure, SNIP $\left[40 \mathrm{cmH}_{2} \mathrm{O}\right.$ to $\left.67 \mathrm{cmH}_{2} \mathrm{O}\right]$ and peak cough flow, PCF (300l/min to $\left.450 \mathrm{l} / \mathrm{min}\right)$ were seen after the first 5 weeks of training before any adjustments were made to EMST ${ }^{\mathrm{TM}}$ pressures. MEP continued to improve at weeks 12 and 32, SNIP and PCF plateaued after week 5 with a drop in PCF seen at week 32 (Table 3). Overall improvements were also seen in functional vital capacity (FVC), percentage predicted functional vital capacity (\%FVC), forced expiratory volume in second (FEV1) and percentage predicted forced expiratory volume in second (\%FEV1). No improvements were seen in swallow physiology (MBSImPC), safety or efficiency (DIGEST; PAS), tongue strength (IOPI), swallowing symptoms (SSQ), mealtime experience (EAT-10), motor speech abilities (Frenchay Dysarthria Assessment) or experience of dysarthria (Dysarthria Impact Profile).

The patient reported no adverse effects of the training. One five-day break from the training programme was required at week 30 due to illness which was presumed to be a viral upper respiratory tract infection. 
Figure 1 shows the changes in the two dependent variables (maximum expiratory pressure and peak cough flow) most strongly associated with cough clearance and subglottic pressure generation which EMST programme was designed to target. Changes are shown across both time (in weeks) and EMST resistance $(\mathrm{cmH} 2 \mathrm{O})$.

\section{Discussion}

This is the first study to examine the feasibility, acceptability, and clinical outcomes of EMST in a person with DM1. Improvements across respiratory domains including MIP, MEP, SNIP and PCF were seen in the first five weeks of training as the number of repetitions were increased. Continued improvements in MEP were evident after a further 6 and 27 weeks of training as the load increased from $24 \mathrm{cmH}_{2} \mathrm{O}$ (approx.) at week 5 to $54 \mathrm{cmH}_{2} \mathrm{O}$ (approx.) at week 27 . This mirrors findings in other patient populations $[15,20,21]$ although we did not observe changes in swallowing outcome measures.

EMST was expected to improve respiratory function by increasing the force generating capacity of expiratory muscles. These improvements were evident in the patient's MEP which increased by a factor of $2.5(153 \%)$ and PCF which increased by a factor of $1.3(30 \%)$ to $1201 / \mathrm{min}$ above the threshold of concern for self-clearance of respiratory infection [23]. This improved expiratory capability should help mitigate risk of infection from aspiration and secretion accumulation which occur as swallowing function worsens.

We cannot exclude the possibility that skill rather than strength-based training could explain the improvements in respiratory outcome measures. This skill-based hypothesis would account for the improvements in MEP and PCF before upward titration of EMST resistance as well as explain improvements in MIP and SNIP. A sham intervention would be required to differentiate between improvements due to skill-training and motivation and biological as 
well as functional outcome measures would be required to understand the mechanism of improvement associated with EMST.

A skill-based theory could explain the absence of improvement in swallowing outcome measures previously witnessed in other populations. The maximum EMST pressures for this patient were lower than those used in Parkinson's disease and ALS $[16,20,21]$. It is possible that the inherent respiratory weakness associated with DM1 prevented the patient from reaching the EMST thresholds required to strength-train the muscles of the pharynx and larynx. Improvements seen in other patient groups may be reflective of a less severely impaired respiratory system as well as differences in disease pathophysiology. It is also possible that outcome measures are not sensitive enough to capture more subtle changes in swallowing.

Whilst the characteristics and disease trajectory of this patient would be considered representative of adult-onset DM1, variability in disease severity means the suitability of EMST in this patient population is difficult to appraise. The patient's motivation and engagement with EMST may not be echoed in other patients with a condition in which apathy and anosognosia are widely recognised [24]. It is possible that changes in respiratory outcomes were due to the baseline assessment being conducted on a 'bad day' though retrospective review of respiratory and swallowing outcome measures from 12 and 24 months previous reassured us that baseline measures were representative of the patient's function.

\section{Recommendations}


Whilst further work to understand the biological and functional training effects of EMST is required, this case has highlighted the potential applicability of EMST in optimising respiratory function and managing risk of respiratory infection for people with DM1.

We suggest that training programmes and hardware will require tailoring and/or adaptation to meet the needs of this patient group. The benefit versus burden of extending training programmes beyond the recommended 6-8 weeks [23] should be carefully considered given that the biggest improvements for this individual were witnessed in the first five weeks of training.

Future studies are required to understand the ceiling and detraining effects of EMST in the DM1 population as well as elucidate the disease modifying potential of this active intervention as well as its biological effect.

\section{Acknowledgements}

With thanks to Charlotte Massey, Highly Specialist Physiotherapist who undertook the spirometry assessments for this case.

\section{References}

[1] Emery AE. Population frequencies of inherited neuromuscular diseases - A world survey. Neuromuscul Disord 1991;1(1): 19-29. DOI: 10.1016/0960-8966(91)90039-u

[2] Turner C, Hilton-Jones D. Myotonic dystrophy: Diagnosis, management and new therapies. Curr Opin Neurol 2014;27: 599-606. DOI: 10.1097/WCO.0000000000000128 
[3] Lo Mauro A, Aliveri A. Physiology of respiratory disturbances in muscular dystrophies. Breath (Sheff) 2016;12(4):318-327.

[4] Martorell L, Monckton DG, Sanchez A, de Mumain L, Baiget, M. Frequency and stability of the myotonic dystrophy type 1 premutation. Neurology 2001;56(3):328-35. DOI:

10.1212/wnl.56.3.328

[5] Boitano LJ. Management of airway clearance in neuromuscular disease. Respir Care 2006;51(8): 913-22.

[6] Mathieu J, Allard P, Potvin L, Prévost C, Bégin P. 10-year study of mortality in a cohort of patients with myotonic dystrophy. Neurology 1999; 52(8):1658-62. DOI:

10.1212/wnl.52.8.1658

[7] Consensus-based Care Recommendations for Adults with Myotonic Dystrophy Type 1 https://www.myotonic.org/sites/default/files/MDF_2018_CareConsiderationsDM1_2019_1 4.pdf

[8] Hammarén E, Lindberg C, Kjellby-Wendt G. Effects of a balance exercise programme in myotonic dystrophy type 1: A pilot study. European Journal of Physiotherapy 2015;17:12331. DOI:10.3109/21679169.2015.1049204

[9] Brady LI, MacNeil LG, Tarnopolsky MA. Impact of habitual exercise on the strength of individuals with myotonic dystrophy type 1. Am J Phys Med Rehabil 2014;93:739-46. DOI: 10.1097/phm.0000000000000088

[10] Voet NB, van der Kooi EL, Riphagen, II, Lindeman E, van Engelen BG, Geurts AC. Strength training and aerobic exercise training for muscle disease. Cochrane Database Syst Rev 2013;9(7):CD003907. DOI: 10.1002/14651858.CD003907.pub4

[11] Boerio D, Lefaucheur JP, Bassez G, Hogrel JY. Central and peripheral components of exercise related fatigability in myotonic dystrophy type 1. Acta Neurol Scand 2012;125(1):38-46. DOI: 10.1111/j.1600-0404.2011.01497.x 
[12] Kierkegaard M, Harms-Ringdahl K, Edstrom L, Widen Holmqvist L, Tollback A. Feasibility and effects of a physical exercise programme in adults with myotonic dystrophy type 1: a randomized controlled pilot study. J Rehabil Med 2011;43(8):695-702. DOl: $\underline{10.2340 / 16501977-0833}$

[13] Cup EH, Pieterse AJ, Ten Broek-Pastoor JM, et al. Exercise therapy and other types of physical therapy for patients with neuromuscular diseases: a systematic review. Arch Phys Med Rehabil 2007;88(11):1452-64. DOI: 10.1016/j.apmr.2007.07.024

[14] 0. Trenell MI, Thompson CH, Sue CM. Exercise and myotonic dystrophy: a 31P magnetic resonance spectroscopy and magnetic resonance imaging case study. Ann Neurol 2006;59(5):871-2 DOI: 10.1002/ana.20841

[15] Park JS, Oh DH, Chang MY,Kim KM.Effects of expiratory muscle strength training on oropharyngeal dysphagia in subacute stroke patients: A randomised control trial. Journal of Oral Rehabilitation 2016; 43(5):364-372. DOI: 10.1111/joor.12382

[16] Pitts T, Bolser D, Rosenbek J, Troche M, Okun MS, Sapienza C. Impact of expiratory muscle strength training on voluntary cough and swallow function in Parkinson disease. Chest 2009; 135(5):1301-1308. DOI: 10.1378/chest.08-1389

[17] Troche MS, Rosenbek J, Okun MS, Sapienza CM. Detraining outcomes with expiratory muscle strength training in Parkinson disease. Journal of Rehabilitation Research and Development 2014;51(2):305-310. DOI: 10.1682/JRRD.2013.05.0101

[18] Brooks M, McLaughlin E,Shields N. Expiratory muscle strength training improves swallowing and respiratory outcomes in people with dysphagia: a systematic review. International Journal of Speech-Language Pathology 2019; 21(1):89-100. DOI: 10.1080/17549507.2017.1387285

[19] Tabor LC, Rosado KM, Robison R, Hegland K, Humbert IA et al. Respiratory training in an individual with amyotrophic lateral sclerosis. Ann Clin TransI Neurol. 2016; 3(10): 819823. DOI: $10.1002 / a c n 3.342$ 
[20] Plowman EK, Watts SA, Tabor L, Robison R1, Gaziano J, Domer AS et al. Impact of expiratory strength training in amyotrophic lateral sclerosis. Muscle Nerve 2016; 54(1):48-

53. DOI: $10.1002 /$ mus. 24990

[21] Plowman EK, Tabor-Gray L, Rosado KM, Vasilopoulos T, Robison R, Chapin JL et al. Impact of expiratory strength training in amyotrophic lateral sclerosis: Results of a randomized, sham-controlled trial. Muscle Nerve. 2019; 59(1):40-46. DOI:

$10.1002 /$ mus. 26292

[22] Sapienza CM, Troche M. Respiratory Muscle Strength Training: Theory and Practice. San Diego: Plural publishing; 2011.

[23] Bach JR, Ishikawa Y, Kim H. Prevention of pulmonary morbidity for patients with Duchenne muscular dystrophy. Chest 1997; 112(4):1024-8. DOI: 10.1378/chest.112.4.1024

[24] Baldanzi S, Bevilacqua F, Lorio R, Volpi L, Simoncini C, Petrucci, A et al. Disease awareness in myotonic dystrophy type 1: an observational cross-sectional study. Orphanet Journal of Rare Diseases 2016; 4(11):34. DOI: 10.1186/s13023-016-0417-z

[25] Hammer, MJ and Hutcheson, KA. Quarter-Turn Method and Guide for Selecting Expiratory Muscle Strength Training Target Values for Treatment. Dysphagia Research Society 26th Anniversary Annual Meeting March 15-17, 2018 Renaissance Baltimore Harborplace Hotel, Baltimore, Maryland. Dysphagia 2019; 34: 418-19. 
Figure 1: Changes in Maximum Expiratory Pressure (MEP) and Peak Cough Flow (PCT) during the period Expiratory Muscle Strength Training (EMST) according to length of training period (Fig.1a \& c) and resistance (Fig $1 b$ \& d).

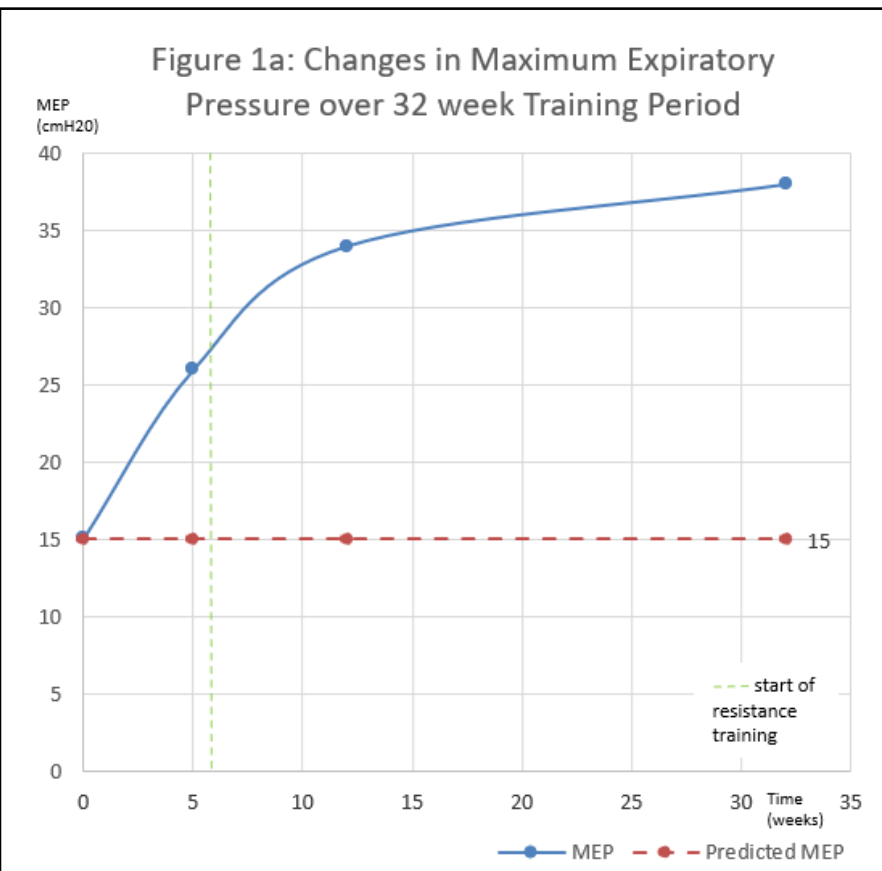

Figure 1c: Changes in Peak Cough Flow over

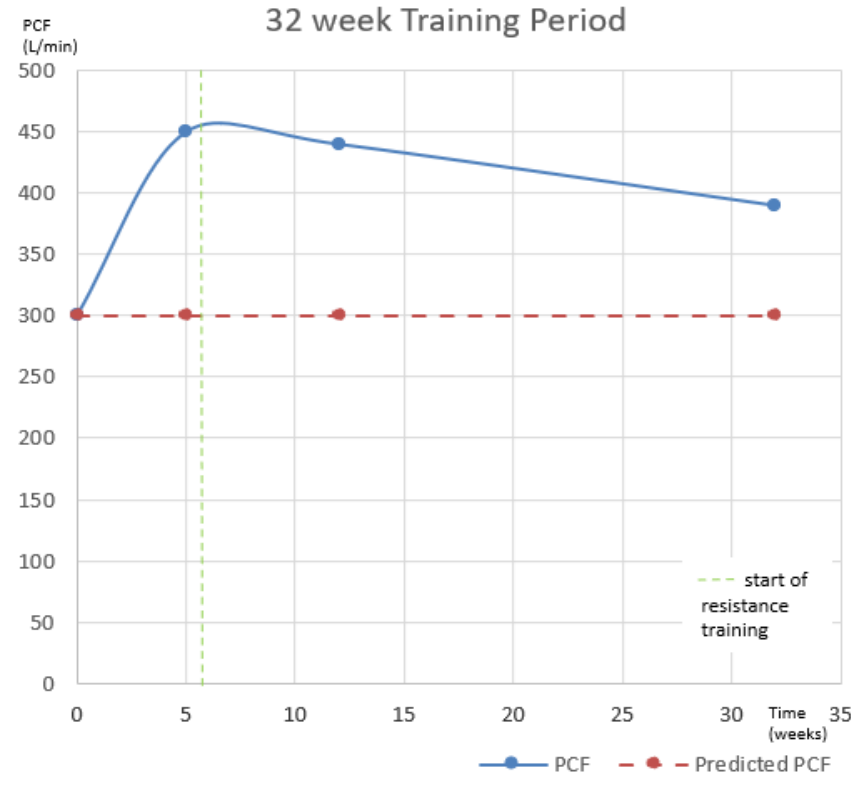

Figure 1b: Changes in Maximum Expiratory $\underset{(\mathrm{cmH20})}{\text { MEP }}$ Pressure associated with EMST Resistance

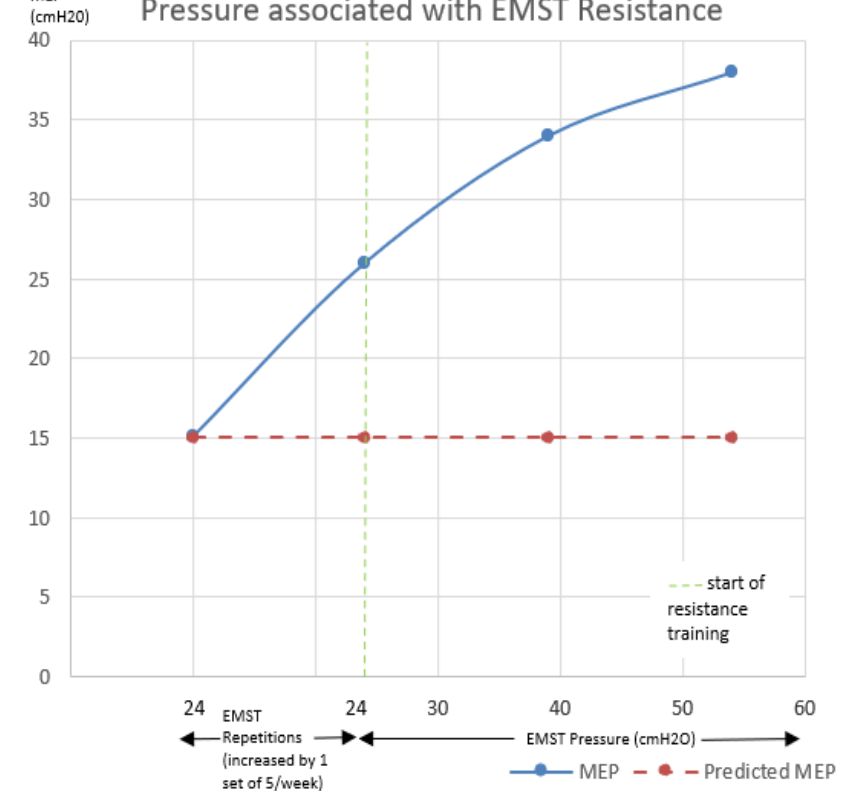

Figure 1d: Changes in Peak Cough Flow PCF associated with EMST Resistance

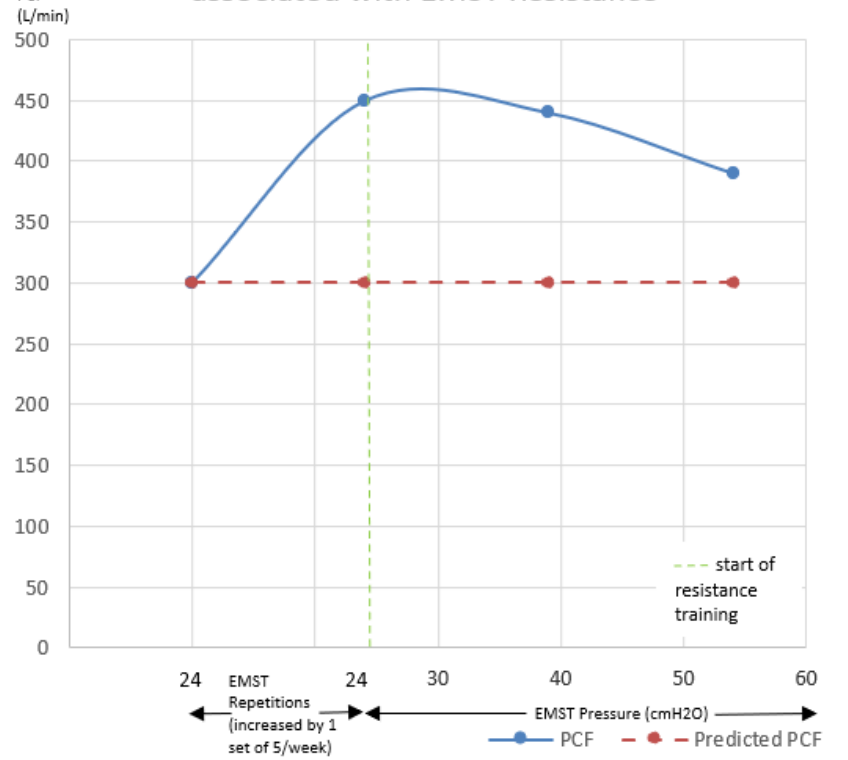


Table 1: Respiratory and Bulbar outcome measures for EMST.

\begin{tabular}{|c|c|}
\hline Assessment & Tool \\
\hline \multicolumn{2}{|l|}{ Respiratory } \\
\hline Functional Vital Capacity (FVC) & $\begin{array}{l}\text { Calibrated MicolabTM Spirometer, Vyaire medical IL, } \\
\text { USA* }\end{array}$ \\
\hline $\begin{array}{l}\text { Forced expiratory volume in one } \\
\text { second (FEV1) }\end{array}$ & $\begin{array}{l}\text { Calibrated MicolabTM Spirometer, Vyaire medical IL, } \\
\text { USA* }\end{array}$ \\
\hline Maximum Expiratory Pressure (MEP) & $\begin{array}{l}\text { Calibrated MicroRPM Respiratory Muscle Testing, Vyaire } \\
\text { medical IL, USA* }\end{array}$ \\
\hline Maximum Inspiratory Pressure (MIP) & $\begin{array}{l}\text { Calibrated MicroRPM Respiratory Muscle Testing, Vyaire } \\
\text { medical IL, USA* }\end{array}$ \\
\hline Peak Cough Flow (PCF) & Mini-Wright Peak Flow Metre* \\
\hline Sniff Nasal Inspiratory Pressure (SNIP) & $\begin{array}{l}\text { Calibrated MicroRPM Respiratory Muscle Testing,Vyaire } \\
\text { medical IL, USA* }\end{array}$ \\
\hline \multicolumn{2}{|l|}{ Bulbar } \\
\hline Tongue Strength (kPa) & lowa Oral Performance Instrument (IOPI) ${ }^{1 *}$ \\
\hline Patient-reported swallow symptoms & $\begin{array}{l}\text { Sydney Swallow Questionnaire (SSQ) })^{2} \text { Maximum score } \\
1700 \text {, high scores indicative of increased severity of } \\
\text { symptoms. } \\
\text { Eating Assessment Tool (EAT-10) }{ }^{3} \text { Maximum score 40, } \\
\text { high scores indicative of increased severity of symptoms. }\end{array}$ \\
\hline Swallow physiology & $\begin{array}{l}\text { Videofluoroscopy conducted as per the Modified Barium } \\
\text { Swallow Impairment Profile (MBSImP (C) Maximum score }\end{array}$ \\
\hline Swallow Safety \& Efficiency & $\begin{array}{l}\text { 55, high scores indicative of more severe impairment. } \\
\text { Dynamic Imaging Grade of Swallowing Toxicity (DIGEST) } \\
\text { Grade } 0-4 \text {, high grade indicative high-risk symptoms. The } \\
\text { Penetration-Aspiration Scale (PAS) }{ }^{5} \text { Scale 1-8, high score } \\
\text { indicative of more severe symptoms. }\end{array}$ \\
\hline Oral Intake & $\begin{array}{l}\text { Functional Oral Intake Scale (FOIS) })^{6} \text { Grading scale 1-7, } \\
\text { low grade indicative of more restricted oral intake. }\end{array}$ \\
\hline Motor Speech & Frenchay Dysarthria Assessment $^{7}$ \\
\hline Speech Impact & Dysarthria Impact Profile ${ }^{8}$ \\
\hline
\end{tabular}

*Best of three attempts.

\footnotetext{
${ }^{1}$ IOPI Medical https://iopimedical.com/medical-professionals/.

${ }^{2}$ Wallace KL, Middleton S, Cook IJ. Development and validation of a self-report symptom inventory to assess the severity of oral-pharyngeal dysphagia. Gastroenterology 2000;118:678-687.

${ }^{3}$ Belafsky PC, Mouadeb DA, Rees CJ, Pryor JC, Postma GN, Allen J et al. Validity and reliability of the Eating Assessment Tool (EAT-10) 2008; Ann Otol Rhinol Laryngol 117(12);919-24.

${ }^{4}$ Hutcheson K, Barrow MP, Barringer DA, Knott JK, Lin HY, Weber RS et al. Dynamic Imaging Grade of Swallowing Toxicity (DIGEST): Scale development and validation. Cancer. 20171;123(1):62-70.

${ }^{5}$ Rosenbek JC, Robbins JA, Roecker EB, Coyle JL, Wood JL. A penetration-aspiration scale. Dysphagia. 1996 Spring;11(2):93-8.

${ }^{6}$ Crary MA, Mann GD, Groher ME. Initial psychometric assessment of a functional oral intake scale for dysphagia in stroke patients. Arch Phys Med Rehabil. 2005;86(8):1516-20.

${ }^{7}$ Enderby, P. The Frenchay Dysarthria Assessment. British Journal of Disorders of Communication 1980;15;165173.

${ }^{8}$ Walshe M, Peach RK, Miller N. Dysarthria impact profile: development of a scale to measure psychosocial effects.Int J Lang Commun Disord. 2009;44(5):693-715.
} 
Table 2: Sequential increase in resistance of EMST $150^{\mathrm{TM}}$ device.

\begin{tabular}{|c|c|l|}
\hline \multirow{2}{*}{$\begin{array}{c}\text { Training } \\
\text { week }\end{array}$} & \multicolumn{2}{|c|}{ EMST150 ${ }^{\text {TM }}$ Setting } \\
\cline { 2 - 3 } & Repetitions & \multicolumn{1}{|c|}{$\begin{array}{c}\text { Pressure [size of turn*] } \\
\left(\mathrm{cm} \mathrm{H}_{2} \mathrm{O}^{* *}\right)\end{array}$} \\
\hline 1 & $2 \times 5$ & {$[0] 24$} \\
\hline 2 & $3 \times 5$ & {$[0] 24$} \\
\hline 3 & $4 \times 5$ & {$[0] 24$} \\
\hline 4 & $4 \times 5$ & {$[0] 24$} \\
\hline 5 & $5 \times 5$ & {$[0] 24$} \\
\hline $6-7$ & $5 \times 5$ & {$[1 / 8] 24+3.75=27.75$} \\
\hline $8-10$ & $5 \times 5$ & {$[1 / 4] 24+7.5=31.75$} \\
\hline $11-14$ & $5 \times 5$ & {$[1 / 2] 24+15=39$} \\
\hline $15-18$ & $5 \times 5$ & {$[3 / 4] 24+22.5=46.5$} \\
\hline $19-26$ & $5 \times 5$ & {$[7 / 8] 24+26.25=50.25$} \\
\hline $27-32$ & $5 \times 5$ & {$[$ full] $24+30=54$} \\
\hline
\end{tabular}

* Cumulative from zero **Pressure increment based on https://www.emst150.com/wp-content/uploads/2019/11/Calibration.pdf 
Table 3: Respiratory and Bulbar Outcome Measures at weeks 5, 13 and 32.

\begin{tabular}{|c|c|c|c|c|c|c|c|c|c|}
\hline \multicolumn{10}{|c|}{ Respiratory Outcome Measures } \\
\hline & FVC & \%FVC & FEV1 & \%FEV1 & MEP & MIP & PCF & SNIP & \\
\hline Week 0 & 2.14 & $58 \%$ & 2.49 & $74 \%$ & 15 & 26 & 300 & 40 & \\
\hline Week 5 & 2.89 & $68 \%$ & 2.57 & $76 \%$ & 26 & 42 & 450 & 67 & \\
\hline Week 12 & 2.95 & $84 \%$ & 2.71 & $89 \%$ & 34 & 72 & 440 & 67 & \\
\hline Week 32 & 2.95 & $84 \%$ & 2.67 & $88 \%$ & 38 & 52 & 390 & 69 & \\
\hline Overall Change & +0.81 & $+26 \%$ & +0.18 & $+14 \%$ & +23 & +26 & +90 & +29 & \\
\hline \multicolumn{10}{|c|}{ Bulbar Outcome Measures } \\
\hline & IOPI & SSQ & EAT-10 & FOIS & MBSImPC & PAS & DIGEST & Frenchay & DIP \\
\hline Week 0 & 24 & 937 & 23 & 6 & $6,17,0$ & 3 & 2 & Completed & Completed \\
\hline Week 12 & 20 & 935 & 22 & 6 & $6,17,0$ & 3 & 2 & Completed & Completed \\
\hline Week 32 & 20 & 900 & 21 & 6 & $6,17,0$ & 3 & 2 & Completed & Completed \\
\hline Overall Change & -4 & -37 & -21 & 0 & 0 & 0 & 2 & Nil & Nil \\
\hline
\end{tabular}

FVC functional vital capacity (litres); \%FVC percentage of predicted functional vital capacity (\%); FEV1 forced vital capacity in 1 second (litres); \%FEV1 percentage of predicted forced vital capacity in 1 second (\%); MEP maximum expiratory pressure (cmH2O); MIP maximum inspiratory pressure (cmH2O); PCF peak cough flow (L/min); SNIP sniff nasal inspiratory pressure (cmH2O); IOPI lowa Oral Performance instrument (KPa); SSQ Sydney Swallow Questionnaire (scored out of 1700); EAT-10 Eating Assessment Tool (scored out of 40); FOIS Functional Oral Intake Scale (7-point scale); MBSImP@ Modified Barium Swallow Impairment Profile (oral total sum, pharyngeal total sum, oesophageal total sum - oral domain scored out of 22; pharyngeal domain out of 29; oesophageal out of 4); PAS Penetration-Aspiration Scale (scored 1-8) DIGEST Dynamic Imaging Grade of Swallowing Toxicity (grade 0-4); Frenchay Frenchay Dysarthria Assessment (not scored); DIP Dysarthria Impact Profile (not scored). 